\title{
Network dynamics in scientific knowledge acquisition: an analysis in three public universities in the state of Bahia*
}

\author{
Rogério Hermida Quintella** \\ Elizabeth Jorge da Silva Monteiro de Freitas*** \\ Andréa Cardoso Ventura**** \\ Morjane Armstrong Santos***** \\ Liliane Queiroz Antonio******
}

\begin{abstract}
Summary: 1. Introduction; 2 . Reference theoretical frame; 3. Methodological strategy; 4. Analysis of the UFBA's knowledge networks and the role of its Graduation Program on Chemistry; 5. The UFBA's influence on chemistry knowledge networks at the Uneb and Uesc; 6 . The chemistry networks in state of Bahia as a small worlds phenomenon; 7. Conclusions.
\end{abstract}

SumÁrio: 1. Introdução; 2. Quadro de referência teórica; 3. Estratégia metodológica; 4. Análise de redes do conhecimento da UFBA e o papel do seu Programa de

\footnotetext{
* Article received in June and accepted in Oct. 2009.

$* * \mathrm{PhD}$ in strategic management of technology (University of Brighton, UK). Professor at Universidade Federal da Bahia (UFBA). Address: Nacit — Escola de Administração da UFBA — Av. Reitor Miguel Calmon, s/n — Vale do Canela — CEP 40110-903, Salvador-BA, Brazil. E-mail: rogerio@ufba.br.

$* * *$ MSc in business administration (MScBA) (Universidade Federal da Bahia, UFBA). General coordinator of the graduate school of Faculdade Social da Bahia and researcher at UFBA. Address: Faculdade Social da Bahia - Av. Oceânica, 2717 - Ondina - CEP 40170-010, Salvador-BA, Brasil. E-mail: elizabethjfreitas@hotmail.com.

$* * * *$ MSc in business administration (MScBA) (Universidade Federal da Bahia, UFBA). Researcher at UFBA. Address: Nacit — Escola de Administração da UFBA — Av. Reitor Miguel Calmon, s/n — Vale do Canela - CEP 40110-903, Salvador-BA, Brasil. E-mail: andreaventurassa@gmail. com.

$* \ldots * * *$ International relations expert (Universidade Federal da Bahia, UFBA). Secretary and researcher at UFBA. Address: Nacit — Escola de Administração da UFBA — Av. Reitor Miguel Calmon, s/n — Vale do Canela — CEP 40110-903, Salvador-BA, Brazil. E-mail: morjane.nacit@ yahoo.com.br.

$* * * * * * \mathrm{PhD}$ in education, science and technology (Unicamp). Visiting professor at Universidade Estadual de Santa Cruz (Uesc). Address: Universidade Estadual de Santa Cruz (Administration and Accounting Department) - Campus Soane Nazaré de Andrade, km 16 — Rodovia Ilhéus-Itabuna — CEP 45662-000 — Ilhéus-BA, Brasil. E-mail: liliqueiroz_24@yahoo.com.br.
} 
Graduação em Química; 5. A influência da UFBA em redes de conhecimento em química na Uneb e Uesc; 6 . As redes de química no estado da Bahia como pequenos fenômenos no mundo; 7. Conclusões.

KeY words: knowledge networks; scientific production; scientific knowledge; state of Bahia.

Palavras-chave: redes de conhecimento; produção científica; conhecimento científico; estado da Bahia.

This paper aims to cast some light on the dynamics of knowledge networks in developing countries by analyzing the scientific production of the largest university in the Northeast of Brazil and its influence on some of the remaining regional research institutions in the state of Bahia. Using a methodology test to be employed in a larger project, the Universidade Federal da Bahia (UFBA) (Federal University of Bahia), the Universidade do Estado da Bahia (Uneb) (State of Bahia University) and the Universidade Estadual de Santa Cruz (Uesc)'s (Santa Cruz State University) scientific productions are discussed in one of their most traditionally expressive sectors in academic production - namely, the field of chemistry, using social network analysis of co-authorship networks to investigate the existence of small world phenomena and the importance of these phenomena in research performance in these three universities. The results already obtained through this research bring to light data of considerable interest concerning the scientific production in unconsolidated research universities. It shows the important participation of the UFBA network in the composition of the other two public universities research networks, indicating a possible occurrence of small world phenomena in the UFBA and Uesc networks, as well as the importance of individual researchers in consolidating research networks in peripheral universities. The article also hints that the methodology employed appears to be adequate insofar as scientific production may be used as a proxy for scientific knowledge.

Dinâmicas de aquisição das redes de conhecimento científico: uma análise em três universidades públicas do estado da Bahia

O propósito deste artigo é lançar luz sobre a dinâmica das redes de conhecimento, nos países em desenvolvimento, por meio da análise da produção científica da maior universidade do Nordeste do Brasil (UFBA) e sua influência sobre algumas instituições regionais de pesquisa no estado da Bahia. Através de um teste de metodologia, as produções científicas, especificamente no campo da química, da Universidade Federal da Bahia (UFBA), da Universidade do Estado da Bahia (Uneb) e da Universidade Estadual de Santa Cruz (Uesc) foram minuciosamente analisadas e cruzadas. Por meio da análise de redes sociais investigou-se a exis- 
tência de pequenos fenômenos do mundo e a importância destes fenômenos na realização da pesquisa nas três universidades. Os resultados obtidos com a pesquisa elucidaram dados de grande interesse sobre a produção científica nessas universidades e comprovaram a importante participação da rede UFBA e das outras duas instituições públicas de pesquisa, bem como a importância dos pesquisadores na consolidação de redes. Este artigo também sugere que a metodologia pode ser adequada à medida que a produção científica seja utilizada como um substituto para o conhecimento científico.

\section{Introduction}

Innovation, as a theme, has been greatly discussed as a source of differentiation and competitive advantage for organizations, states and countries that operate in an economy of global dimensions. Taking the economic literature as a reference, the thesis that innovation inside a society is capable of promoting its development has led governments at every level and in different regions of the world to formulate policies that might stimulate research, development and innovation (RandDandI) in the productive environment.

Inserted in this scenario, Brazil shares this view and has sought to promote innovation by means of public laws, as witnessed by the passing of the so called Innovation Law (Law no 10.973/04), with the purpose of reaching technological autonomy and the full industrial development of the country. In the context of this law, innovation is defined as: "the introduction of novelty or improvement to the productive or social environment which might result in new products, processes or services" (Brazil, 2004).

If scientific and technological innovations have received special attention at the Federal Government level, the same may also be said about the attention paid to the theme at the State level, concerned with raising the standard of competitiveness of its industries, service rendering and other organizations.

Usually backed by state-run foundations for the support of research, countless programs for the support of RandDandI have been regionally discussed and approved, aiming to increase the innovation rate in the Brazilian states so as to guarantee their competitiveness.

This paper is the result of one of these projects, in this case, a study conducted in state of Bahia with the goal of understanding the dynamics in 
the generation of scientific knowledge in its main research institution, the Universidade Federal da Bahia (UFBA) (Federal University of Bahia), and its influence on the state's smaller public universities. An important goal is to present its intermediate results from the initial research of the project and bring to light some of its initial results of wider interest. These results show the dynamics of the UFBA's network of co-authorship in the field of chemistry and its impact on the Universidade do Estado da Bahia (Uneb) (State of Bahia University) and the Universidade Estadual de Santa Cruz (Uesc) (Santa Cruz State University). ${ }^{1}$

If, on the one hand, the difficulty of finding reliable technological and innovation indicators is admitted, as mentioned by Furtado (1996) and Carvalho et al. (1999), on the other hand, it is known how to measure the nuts and bolts competences of this process with relative ease, i.e., the scientific competences. The importance of generating scientific knowledge in sources outside of businesses is widely admitted in innovation studies. In this sense, as an example, we may mention the European Community Innovation Survey of 1997 and 2000 (Huang, Arundel and Hollanders, 2008) and the work of Carvalho et al. (2006), which show the respective relevance of outside innovation sources in Europe and Brazil.

In this paper, the indexed scientific production at the ISI Web of Knowledge ${ }^{2}$ (WoK) and Web of Science (WoS) was used as a proxy from the scientific knowledge production in the major state universities and research centers located in the state of Bahia from 1970 onwards. Figure 1 shows state of Bahia total scientific production (all areas).

\footnotetext{
${ }^{1}$ Later on, other important areas of knowledge of this university will be studied based upon the same methodology.

${ }^{2}$ ISI-Web of Knowledge is an online academic database provided by Thomson Scientific's Institute for Scientific Information. It provides access to many databases and other resources: Web of Science (including Science Citation Index (SCI), Social Sciences Citation Index (SSCI), Arts and Humanities Citation Index (AandHCI), Biological Abstracts, Index Chemicus, and Current Chemical Reactions, covering about 8,700 leading journals in science, technology, social sciences, arts, and humanities), ISI Proceedings, Current Contents Connect, Medline, ISI Essential Science Indicators, Journal Citation Reports (two editions: Science and Social Sciences), in-cites, Science Watch, ISI HighlyCited.com, Index to Organism Names, andBiologyBrowser.The Web of Knowledge is also called All Databases because it includes, aside from the Web of Science, the base denominated Derwent Innovations Index.
} 


\section{Figure 1}

Total scientific production in the major state universities and research centers located in the state of Bahia in number of indexed articles from 1970 to 2008

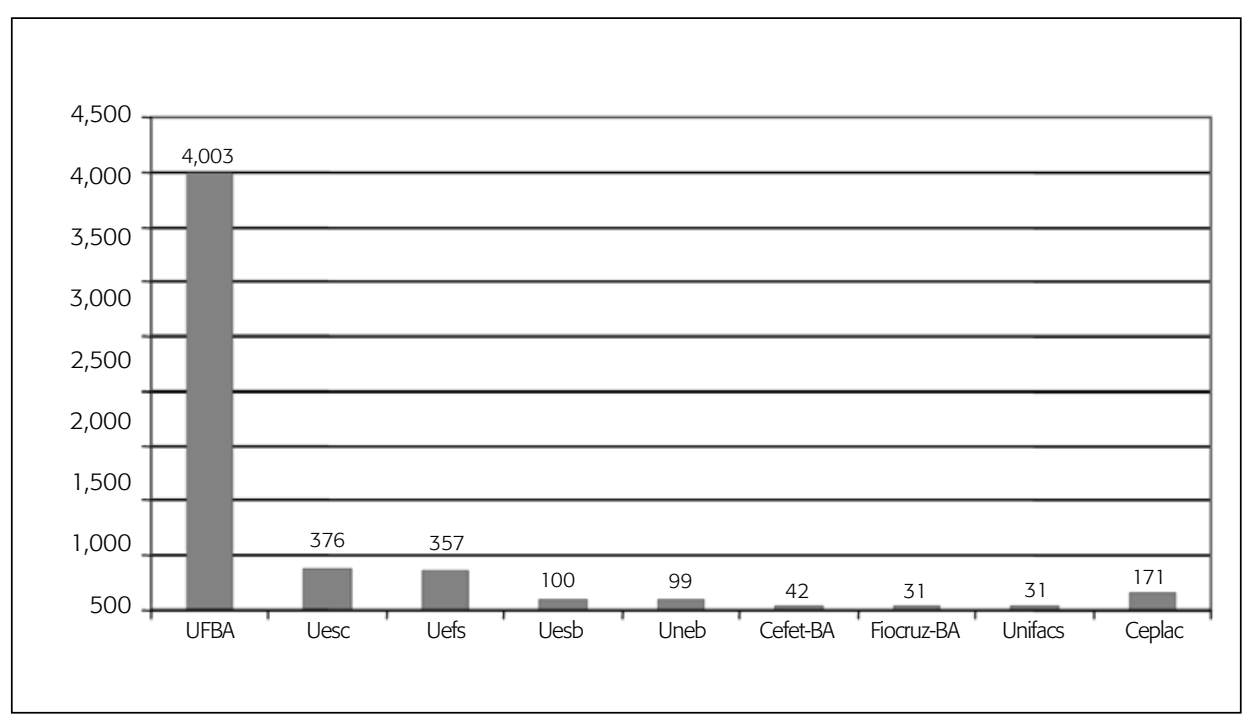

Source: Prepared by the authors based on ISI - Web of Knowledge, 2009.

Figure 1 shows that the UFBA alone holds the highest percentage, with over $78 \%$ of this production. When also considering co-authorships that originate from other institutions, the share of UFBA in the indexed production in the State surpasses 85\% (ISI-WoK, 2009).

Since the results obtained in both the aforementioned databases are very similar (figure 2), only ISI-WoK data shall be used in this article due to the fact that this base adopts a more adequate set of chemistry sub-areas to the goals of the current study, for example, inorganic, organic and analytical chemistry.

For the contextualization of the scientific production dynamics of the UFBA in the national and international context, its comparative production growth is shown in figure 3 comparing the university, Brazil and the world.

As can be seen, during the period under study, while the world scientific production doubled in size, national production grew eight and a half times and the production at the UFBA grew more than ten times. 
Figure 2

Total scientific production comparison chart of the UFBA, indexed by ISI-Web of Knowledge and by the Web of Science



Source: Prepared by the authors, 2009.

Figure 3

Growth comparison of scientific production in the world, Brazil and the UFBA

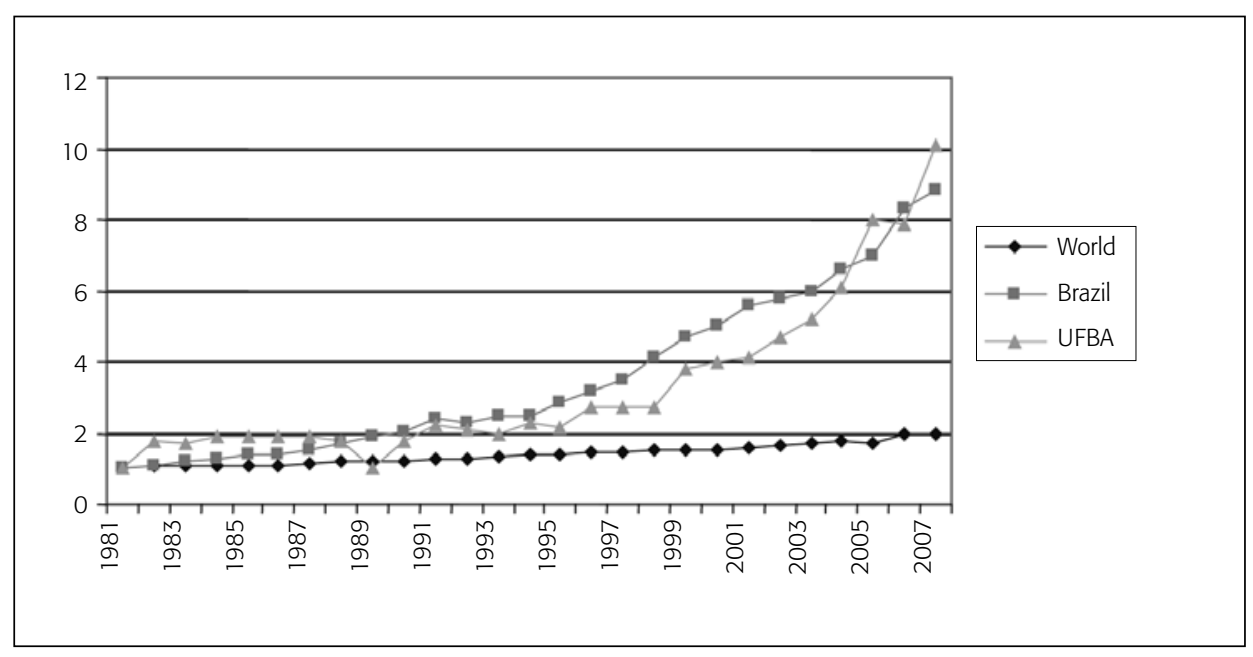

Source: Prepared by the authors based on ISI-Web of Knowledge, 2009.

Having analyzed the importance of the UFBA's scientific production and that of other science and technology institutions in Bahia, it is worth highli- 
ghting that the State is responsible for only roughly $3 \%$ of national scientific production, while its share in the country's Gross National Product is approximately 6\% (Brazilian Institute of Geography and Statistics [IBGE], 2005). The discrepancy between these two percentiles shows that it is necessary to try to identify and map the scientific competences in the institution responsible for almost $80 \%$ of the State's indexed scientific production in order to subsidize and more effectively collaborate with the creation of policies and strategies capable of accelerating its growth even more, as well as its contribution to other local universities aiming to close the gab between the participation of Bahia in the national scientific and economic spheres.

Scientific activity has become increasingly valued as collective entrepreneurship and not only as a result of individual productions. Therefore, the concern over the fragmentation of scientific fields of research has become persistent, for "it is seen as something negative, since it does not allow for the formation of one scientific group which may share the yielded knowledge in their groups, hindering the development of a normal science" (Kuhn, 1978, apud Rossoni and Garrido Filho, 2009:368).

Thus, evaluating the dynamics of scientific knowledge networks may also bring relevant information for the creation of policies capable of accelerating its growth. For that, we employed the social network analysis and the small worlds theory, as presented below.

With this intention, the analysis, so far conducted at a macro level, will be extended to a micro level, dividing the present article into six more sections: theoretical references, methodological strategy, UFBA micro level analysis (of a chosen knowledge network), the UFBA's influence upon other state universities, verification of small worlds phenomenon in chemistry networks and the conclusions.

\section{Reference theoretical frame}

The work developed by university researchers and lecturers is widely recognized as necessary for the creation and formation of knowledge, as well as for the search of solutions to the daily problems of society. In the majority of the scientific works produced by universities, these actors make up interpersonal relationship networks, both intra and inter-institutional, in order to improve learning, speed up the diffusion of knowledge generated as a result, obtain resources for research. The principal aim is to legitimize the importance of their personal contributions and see them recognized. 
The analysis of knowledge networks (and their contribution to the formation of other networks) requires an evaluation of the relationship between their actors (in this context authors), as well as their cooperation dynamics. This has to do with a structure of relations and competences defined as "the set of direct and indirect relationships developed in a delimited space-time moment which are part of a social system" (Machado-da-Silva and Rossoni, 2007:4)

For the social actors, according to Barab et al. (2001), the environment in which they live and the formation of networks among them are fundamental in order to generate information which will test the viability of their comprehension, and with it build up a body of propositions which make up knowledge.

In referring to the scientific production area, the knowledge building process tends to become increasingly dynamic and regenerative. Gibbons et al. (1994) affirms that, in this field, knowledge generation takes place on a nonlinear mode, with their main characteristics being the trans-discipline in knowledge-creation and the social relations between actors as a starting point.

The scientific field, as any social field, is a social system reproducing relations between actors or collectivities, organized as regular social practices (Giddens, 1989; Machado-da-Silva and Rossoni, 2007). Therefore, it is necessary to consider the importance attributed to the social relations in this field, discussing their groups in the network formation.

A social network is a set of people, institutions or organizations which, due to their affinity, share, for instance, work and/or information and, by means of these connections, construct and reconstruct a social structure (Tomaél and Marteleto, 2006) as routinely happens in the scope of programs and research groups.

On a more focused view, Didriksson (2003) defines networks as a set of nodes and their relations, which enable interactions and social organizations, where information and knowledge are key-elements of their processes. According to Casas et al. (2001), due to the knowledge exchange between actors, the networks wind up forming knowledge spaces configured through intrainstitutional relationship, built inside research centers and universities, and the inter-institutional relationship established among the actors themselves, belonging to the same activity. It is these very sets of intra and inter-institutional relationships that are intended to be mapped here.

Sebastián (1999:309) deepens this concept further still, for the purposes of this article by bringing it to the field of scientific research as "coopera- 
tion network modality and [which] are defined as the association of research groups for the accomplishment of group work, usually through research and development projects".

Another aspect pertaining to the discussion about knowledge networks and their relationship with learning is given by Lave and Wenger (1991). These latter articulate the concept of community of practice (which has been associated with knowledge management as people began to see it as a form of social capital of development and knowledge production) articulating the concept of practice community to the learning concept, highlighting the importance of a fundamental process to its functioning, which they denominated legitimate periferical participation. This process deals with the relationship between rookies and veterans, a relationship absolutely institutionalized through the orientation of young master's degree and $\mathrm{PhD}$ students by doctors of a higher professional experience.

The concepts and contributions presented above reinforce the assumption that by sharing ideas (identities), equipment, methods and techniques (artifacts), the actors (community) adopt criteria for the choice of peers, selecting them according to the approach of their interest and which may also be accessible, to the time they hold a certain degree of legitimacy in the field as a whole. This means that network success, formed by researchers (in this article, as authors) will depend on the set of basic rules built and legitimated in their communities. Furthermore, the result of the dynamic in the relationship between them will both influence and be influenced by institutionalized research practices.

In order to analyze a social network, it is necessary to understand its structure, as well as the relationship that builds it. One of structural property of a network is density, which, according to Gnyawali and Madhavan (2001), may be understood through the extension of the interconnection between the actors, i.e., the greater the interconnection, the greater the density and proportionally the greater the shares of effective relations.

The measurements of centrality, density and transitivity make up some of the main structural properties of a network. Among the latter, the measurements of centrality, which divide themselves into three main categories, are highlighted.

The degree of centrality is the number of existing ties with actors from the network. Now, the betweenness centrality is the measurement referring to the number of nodes or subgroups that are interconnected by one single node (it represents the capacity of one specific author to make the link 
between two or more authors not directly connected), while the closeness centrality corresponds to the distance of average proximity of one actor in relation to other actors in the net (Wasserman and Faust, 1994). It is also important to verify the concept of geodesic distance, defined by Barbosa, Byington and Struchiner (2000) as the measurement of the smallest distance between nodes of one network.

One of the main analysis elements of knowledge networks lies in their cohesion. Thus, in the actors' collective behavior of one same group, cohesion serves as the basis for the solidarity and identity of the group, which conceptualizes as a homophyly characteristic (De Nooy, Mrvar and Batagelj, 2005). The presence of homophyly is relatively common in social and knowledge networks, generating groups which, at times, have their own norms, sub-cultures and values. Groups, on the other hand, are here defined as a subnetwork composed of three or more nodes, directly connected (Scott, 2000; Wasserman and Faust, 1994). According to some authors, such as Rossoni and Machado-da-Silva (2008), the homogenization of practices and the presence of a system of common meanings are so powerful that, in the cohesion of subgroups, a great tendency towards isomorphism can also be seen when:

practices are shared and reproduced starting from the graduation programs, from the formal and informal academic meetings, and from the evaluation programs instituted in graduation, either for the evaluation of program quality, or in the evaluation of the articles submitted for journals and annals of scientific events.

(Liberman and Worf, 1997 apud Machado-da-Silva and Rossoni, 2007:3)

In this way, it is believed that the knowledge or scientific production networks will have groups with some characteristics of their own, but, also as institutionalized practices by major groupings.

Structurally, the networks may be dense or diffuse and, relationally, they may have strong of weak connections. Weak connections and diffuse networks are more typical in unstable environments, since they allow for a greater flow of new information, as desired in research networks. Now, strong connections and dense network are common in stable environments, for the information exchange is refined and there is a high level of confidence, cooperation, reciprocity and social control among the actors (Rowley, Behrens and Krackhardt, 2000), which may lead to the isolation of the group and to possible difficulty of access of these actors and new information which may circle outside that restricted environment. 


\section{Small worlds}

In dealing with dynamic sectors, such as those of research and technological innovation, at the same time that institutionalized practices are used, as previously mentioned, the non-redundant information is sought (new information), which finds fertile soil in diffuse networks (Newman, 2001 and 2004; Moody, 2004). Additionally, in several knowledge areas (Wagner and Leydesdirff, 2005 apud Rossoni and Machado-da-Silva, 2008:2), "the scientific field presents a high clustering coefficient although the distance between the researchers may be small, which leads to an understanding that such isolated actors operate as small worlds". According to Watts and Strogatz (1998), in a structure of the small worlds type, unlike the random networks, the distance between the nodes does not increase with the increase of the network. These networks tend to present high reciprocity and social cohesion among the actors. As the attempt to demonstrate shows, the simple idea of cohesion, "is not sufficient to comprehend the mechanisms of knowledge generation by researchers because in high relation density environments, their contents become more and more redundant" (Watts and Strogatz, 1998:3) which is not the tendency when dealing with scientific communities.

The works of two authors (Burt and Granovetter) are particularly important to understanding the small worlds dynamic. Burt (1992) introduces the discussion of "structural holes" to describe the separation between non-redundant contacts. Granovetter (1973), when dealing with the theory of weak connecting forces, demonstrates the importance of this type of connection for the formation of social cohesion. These two works indicate that the individuals with a higher number of weak connections have greater opportunities of mobility, autonomy, cognitive flexibility, and capacity to act in groups, as opposed to those with strong connections which, although forming a great local cohesion, tend to fragment the global network. In this sense, it is important to highlight the concept of structural holes that are the voids which may permit the flow of non-redundant information in networks of low global density and high cohesion and density at the local level, that is, in networks which have strong and cohesive groups, despite being significantly apart from one another.

According to Rossoni and Machado-da-Silva (2008:3), "considering the relation between local relationship structure with the global structure, it is expected that the field of scientific production should be a self-organized system, in which the affiliation mechanisms between researchers in the micro level may reflect in the structuring of the global network". In this relation (local- 
global), which seems contradictory for the analysis of the scientific field, the idea of small worlds, developed by Watts and Strogatz (1998), integrates the cohesion concepts, structural holes and weak ties, where the information does not become redundant, with a cohesion level necessary for the relationship between the actors to become familiar (Uzzi and Spiro, 2005).

In this approach, actors of one network connect each other from one small number of intermediaries, closely grouped, and with little variance in the average distance between the nodes (Watts and Strogatz, 1998). According to Newman (2004) apud Rossoni and Machado-da-Silva (2008:2): "The fundamental assumption of the small worlds phenomenon is that the actors present in a large network may connect from a small group of intermediaries, typically six".

The network dynamics, characterized as small worlds, are largely determined by the tendency of the actors it comprises to reproduce the existing structural properties in the local social relationships, neither abandoning them, nor suddenly breaking up, that is, avoiding the fragmentation of the network. This cohesion contributes to the construction of global structures which, in turn, will support the local structures.

The local networks are formed by researchers who establish direct links to develop research activities. Their composition is more related to the social cohesion between a given number of actors, in which it is expected that homophyly reciprocity mechanisms influence in the creation of generating elements of institutionalized action standards.

(Rossoni and Machado-da-Silva, 2008:2)

If, structurally, on the one hand, there are cohesive groups which share strong, direct, intense and frequent ties (Wasseman and Faust, 1994), on the other hand, they are not found to be totally isolated, having connections, however, weak these may be small worlds phenomena suggest that, even though many actors are not directly connected, they are still connected by few intermediaries (Lazzarini, 2007). On this point, the important role of some actors is highlighted, the intermediaries, who are responsible for the maintenance of these ties and for the flow of information, making them non-redundant.

The small worlds context is then identified basically by means of analysis of two variables: the clustering coefficient (CC), which is a measurement of local density. It indicates the connectivity degree of the actors with whom determinate actor is linked (Lazzarini, 2007), and the average distance (PL) (Watts, 1999; Strogatz, 1998). Quantitatively speaking, in order to charac- 
terize the phenomenon in a network, the same must present the following characteristics:

v the PL rate (the real network PL/the random network PL) should be near 1.0;

v the CC rate (the real network CC/the random network CC) should be greater than 1.0;

v the Q small worlds coefficient (CC rate/PL rate) should be greater than 1.0.

In Uzzi and Spiro's opinion (2005), the behavior of the researchers inserted in the considered small worlds network may be influenced by means of two mechanisms: one structural and the other relational (Rossoni, 2009). The first, structural, indicates that, the greater the Q (small worlds coefficient), the greater the number of connections and consequently, the greater the probability of exchange between the actors; and the second, relational, demonstrates that, the greater the $\mathrm{Q}$, the greater the redundant ties, which leads to greater local cohesion and also greater the exchange of experiences. In this way, it is concluded that the actors' individual productivity may be affected by the configuration of the phenomenon.

\section{Methodological strategy}

This research was preceded by an exploratory study of the UFBA and state of Bahia scientific production in all of its research areas, where chemistry was found as one of its most important areas of competence (measured by its indexed scientific production).

The scientific production from the UFBA presented by the ISI-WoK (figure 2) in the time span of this analysis was 4,003 papers. The field of chemistry ${ }^{3}$ alone yielded 739 articles $^{4}$ between 1979 and 2008. Due to this large volume of production (one of the university's main ones) and the easy access to the information from the Chemistry Institute ${ }^{5}$ and, particularly of its Gra-

\footnotetext{
${ }^{3}$ It is important to highlight that UFBA's scientific production in chemistry cames not only from its Chemistry Institute, but also from several unities (such as those related to physics, medicine, biology, pharmacy and many others) whose production was classified by ISI-Web of Knowledge as "chemistry". This classification is made as a function of the editorial lines of the indexed periodicals where the articles have been published.

${ }^{4}$ One single paper is classified by the ISI-Web of Knowledge in simultaneous and different areas.

${ }^{5}$ It is important to highlight that the production in chemistry from the UFBA is not restricted to the Institute of Chemistry, or to its graduation, comprising the contributions of several units (such
} 
duation Program, the analysis of its network in the formulation of scientific articles was chosen as a starting point for the study.

The Graduation Program in Chemistry at the UFBA began in 1968 at the master's degree level. During its implementation phase, the course was backed by funds from Brazilian Ministry of Education - Inter-American Development Bank and United Nations Development Programme. Within the new goals established by the federal agency for the support and evaluation of graduate education called Capes (Coordenação de Aperfeiçoamento de Pessoal de Nível Superior) for the graduation, the doctoral program in chemistry was initiated (the concentration area being analytical chemistry) in the first semester of 1992. In 1998, the course was expanded with the creation of one more concentration area (organic chemistry). In the Capes evaluation, referring to the triennium of 1998-2000, the course improved its evaluation for a concept 5 (on a scale ranging from 0 to 7 ), and remaining so ever since.

The scientific production of the UFBA in this area over the years is shown in figure 4, below.

Figure 4

\section{The distribution of the indexed production from the UFBA through the years in the field of chemistry}

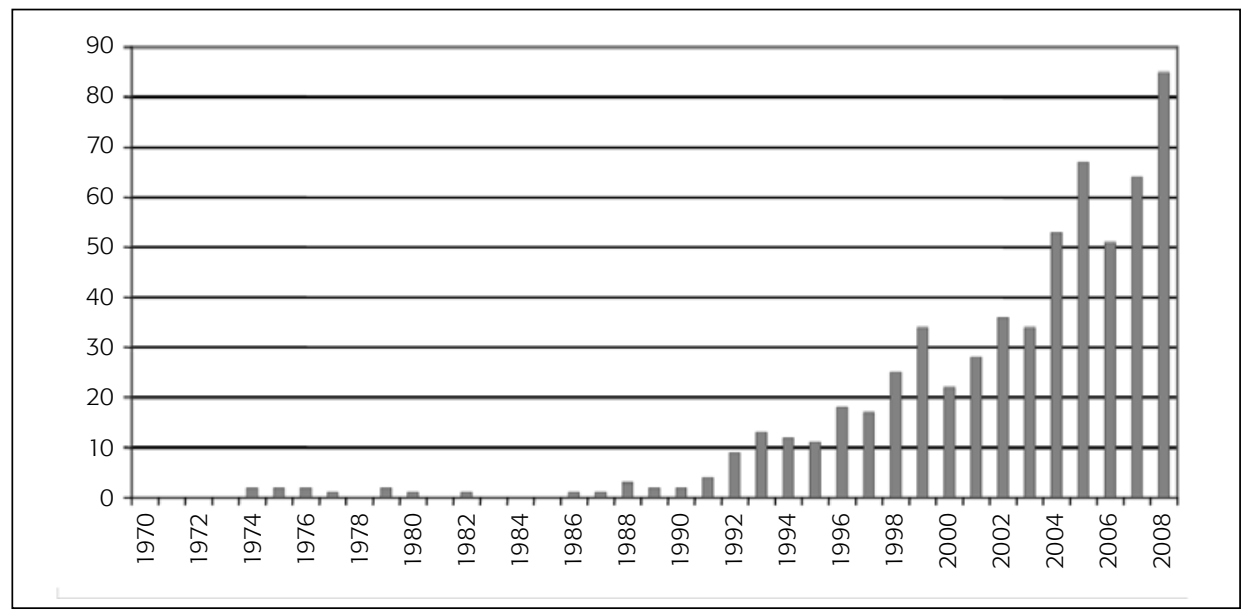

Source: Prepared by the authors based on ISI-Web of Knowledge, 2009.

as physics, medicine, biology, pharmacy and many others) whose production is found classified by the ISI-Web of Knowledge itself as "chemistry". This classification derives from the editorial lines of the indexed journals in which the articles were published. 
Aside from a very significant and growing volume, it is noticeable that this production goes through distinct steps. Up to 1994, for instance, only once was the mark of ten indexed papers per year surpassed. Now, in the following four years, there was an evolution, producing every year more than ten indexed articles, and surpassing twenty papers on 1998. Between 1999 and 2003 the achievement of a new production level is noticeable, now sitting on an average of thirty articles a year. Finally, in the period of 2004 to 2008, a new standard with averages of almost seventy articles a year was achieved.

Due to space restrictions, the title given each period will not be discussed in this article. For logical and historical reasons, each period will be given a nickname centered on the history of the Chemistry Institute's Graduation Program. Thus, it will be called the "heroic period" (a moment in which the unit still did not have minimally adequate infrastructure at its disposal), from 1970 to 1993; the "ripening period" (preparation and initial consequences from the establishment of the doctoral program), from 1994 to 1998; "consolidation period" (when the master's and doctoral programs were consolidated as a single program), from 1999 to 2003; and the "qualification period" (institutional effort to achieve concept 6 by Capes), from 2004 to 2008 .

Due to the intention to produce quantitative relevance in every phase and the space limitations for this article, only the last three of the four periods will be discussed in the data analysis presented as follow.

\section{Data and methodological procedures}

The intention here is to identify the existing relationships in the network of researchers (co-authors) from the UFBA with indexed scientific production by the ISI-Web of Knowledge as "chemistry" and the effect of this network initially on the formation of chemistry networks at the Uneb and the Uesc. In its second stage, this analysis will be extended to the knowledge networks of other institutions, such as Centro Federal de Educação Tecnológica (Cefet) ${ }^{6}$ (Federal Center for Technological Education), Universidade Estadual do Sudoeste da Bahia (Uesb) (Southwest Bahia State University) and others.

It is important to highlight that our choice of the Uneb and Uesc was intended to include respectively the oldest unfolding graduate program in chemistry in the State and a recently created graduation program in a different, although chemistry-related, area (oceanography). ${ }^{7}$ This approach was inten-

\footnotetext{
${ }^{6}$ Cefet was very recently renamed as Instituto Federal de Educação Tecnológica da Bahia.

${ }^{7}$ In the period of 1994 to 2008, in the area of chemistry, the Uesc published 47 indexed articles, the Uneb 60 and the UFBA 739.
} 
ded to allow a multidisciplinary look at the scientific competencies of Bahia's research institutions.

The structural elements of the network of co-authorship were identified by means of quantitative and qualitative social network analysis through the observation of occurrences throughout the three chosen historical periods of the UFBA's Chemistry Graduation Program ("ripening period", from 1994 to 1998; "consolidation period", from 1999 to 2003; and the "qualification period", from 2004 to 2008).

For the data analysis, the main components of the network were used, following the orientation of Newman (2001) and Moody (2004). This analysis is done to guarantee greater trustworthiness to the information found, bearing in mind that the calculation is done keeping the main group of actors in a determined social network as a base.

The scientific production data gathered for the UFBA, ${ }^{8}$ Uneb and Uesc networks from the ISI-WoK database, were tabulated in spreadsheets and refined by means of the Microsoft Excel Dynamic Table resource, considering authors, co-authors and the number of their joint productions. After this phase, the data spreadsheet was carried to the Ucinet 6 for Windows, where the network structure, its components, cohesion and centrality measurements were analyzed.

The authors and co-authors of the scientific works inventoried for this article were displaced in a square matrix, where the relation between two researchers was indicated by the digit one, and the absence of relation indicated by the digit zero. The publications with only one author were ignored, since the objective here is to understand the scientific production based on the dynamics of knowledge networks through networks of co-authorships.

After delimitating the universities scientific knowledge networks, specific calculations to determinate the existence or not of the small worlds phenomena were conducted, using Watts and Strogatz (1998) calculation. Here it is expected to determine whether, despite of the low global network densities, there is a strong cohesion in each of them. It would be seen as short average distance between actors (near 1.0) and a high clustering coefficient (greater than 1.0). All these calculations were performed separately for each of the three periods of analysis.

\footnotetext{
${ }^{8}$ In the mapped networks of this article, the researchers from each studied university also produced in conjunction with researchers of other institutions. In order to extract each institution's network from the ISI-Web of Knowledge database we used as search filters authors who put each institution (and all of their possible acronyms in their addresses).
} 


\section{Analysis of the UFBA's knowledge networks and the role of its Graduation Program on Chemistry}

Table 1 summarizes the main quantitative characteristics ${ }^{9}$ of the knowledge network in chemistry from the UFBA during the three periods under study.

Table 1

Characterization of knowledge networks in chemistry from the UFBA

\begin{tabular}{|lccc|}
\hline & $1994-98$ & $1999-2003$ & $2003-08$ \\
\hline Total authors & 61 & 247 & 669 \\
Density (\%) & 7.22 & 1.37 & 0.43 \\
Average distance & 2.28 & 4.32 & 3.7 \\
Clustering coefficient & 0.747 & 0.703 & 0.714 \\
\hline
\end{tabular}

Source: Prepared by the authors based on research results, 2009.

As seen above, between the first and the second analyzed period, the number of authors from the UFBA in chemistry with indexed articles from ISIWoK more than quadrupled. At the same time the network became less dense and the average distance between the authors doubled, which may be explained by the reduction of the clustering coefficient, which is a local measurement. As for the change from the second to the third period of analysis, the growth rate in the number of authors was lower, although it almost tripled in size, while the network density became even less dense, however the average distance between authors slightly reduced. This set of results seems to indicate that there was a greater nucleation in research groups (in the networks represented by clicks). This observation seems to be confirmed with the rise of the observed clustering coefficient.

Therefore, with the majority of networks formed within the universities, the social network of the area of chemistry from the UFBA has a significant number of actors, although at the same time it represents a raised level of concentration around some more representative researchers for this field, particularly those connected to the chemistry, physics, biology and pharmacy units of the university.

\footnotetext{
${ }^{9}$ For the preparation of table 1 , a main component concept based method was used where all the co-authorship information from the network was summarized in binary tables indicating solely the existence or absence of co-authorships in each possible relationship between the researchers with conjunction publications identified at WoK.
} 


\section{Ripening period (1994 to 1998)}

The knowledge network for the ripening period is illustrated in figure 5, in which all the relationships of co-authorship with two or more publications in the period are shown. ${ }^{10}$ The size of the nodes is proportional to the level of degree centrality of each author and the shades are relative to the number of their co-authorships in the period.

Figure 5

Partial illustration of the knowledge networks in chemistry from UFBA,
between 1994 and 1998

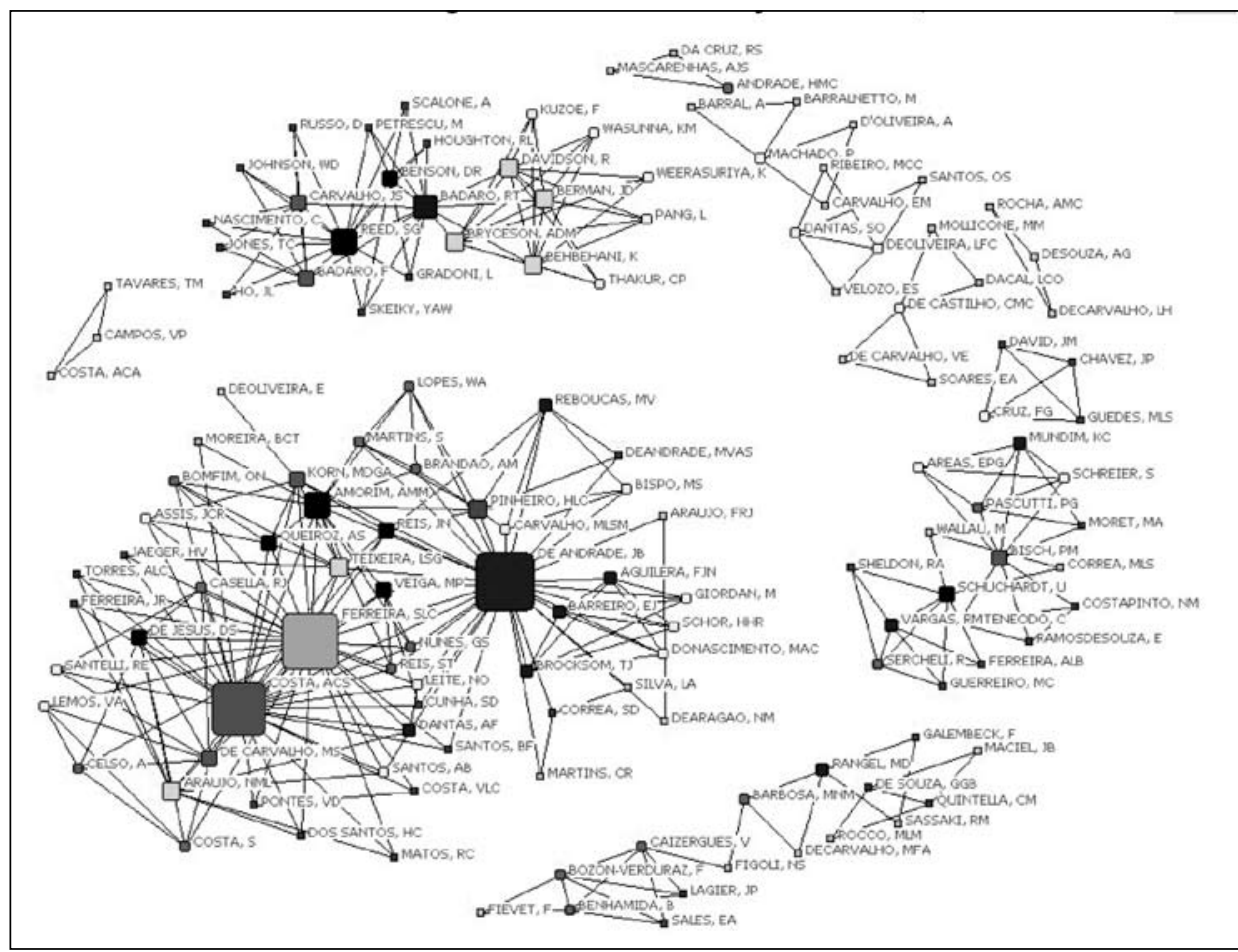

Source: Prepared by the authors based on the research results, 2009.

${ }^{10}$ Due to the great size of these networks, for better visualization of the graphics, in the periods 1 , 2 and 3 , only the relations in which the number of co-authors was respectively equal or superior to 2,3 and 10 were considered. 
The main event of this period was the concentrated effort to raise scientific production from the UFBA's Chemistry Graduation Program (with the intention of getting Capes authorization for the functioning of its doctoral degree program).

In the figure, what is noticeable is that there is a relatively high number of small groups (with more than $60 \%$ of them having, at most, six researchers) and one larger one, centered around three main authors (Ferreira, S. L. C.; Costa, A. C. S. and De Andrade, J. B.). These three researchers and the majority of their co-authors are connected to the Institute of Chemistry and more specifically to its Department of Analytical Chemistry (whose line of research was primarily developed around trace analysis and experimental chemistry). In the second largest group, there appears Badaró, R. T. and Reed, S. G., totaling 24 nodes. This group is dedicated to the study of infectious and parasitic diseases. These two groups together represent $55.22 \%$ of the total nodes depicted in the period. It is worth highlighting the vital role of the individual leaderships identified in only three researchers from the Chemistry Institute. Among them, De Andrade, J. B. was the researcher with the highest degree centrality in this period, totaling 34 connections with other network actors.

\section{Consolidation period (1999 to 2003)}

Figure 6 presents all the network groups with more than five co-authorships in the period. It can be seen that in the previous figure the criterion adopted was to register the groups with more than two authorships, a procedure that may not be repeated here because it makes it difficult to visualize the network due to the large increase in the number of nodes.

Strictly speaking, figure 6 presents three major groups and some small ones. The smallest of them is led by Cunha, S. (presenting only two more authors), the second is led by Malbuisson, L. A. C. and Mundim, K. C. (this group's research on atomic and molecular physics) and the third is led by the same three authors presented in the network from the previous period (Ferreira, S. L. C.; Costa, A. C. S. and De Andrade, J. B.). In this period, it is observed that De Andrade, J. B. presents a significant unattachment from the main group in comparison to the past period. Nevertheless, the strategic importance of this author may be realized on its cut-point position. As can be seen in the figure, in the case of De Andrade absence, the main group on the network would almost be split into three groups. This observation is quantitatively 
supported by table 2, below, showing De Andrade's betweenness centrality growing five times.

\section{Figure 6}

\section{Partial illustration of the knowledge network in chemistry for the UFBA between 1999 and 2003}

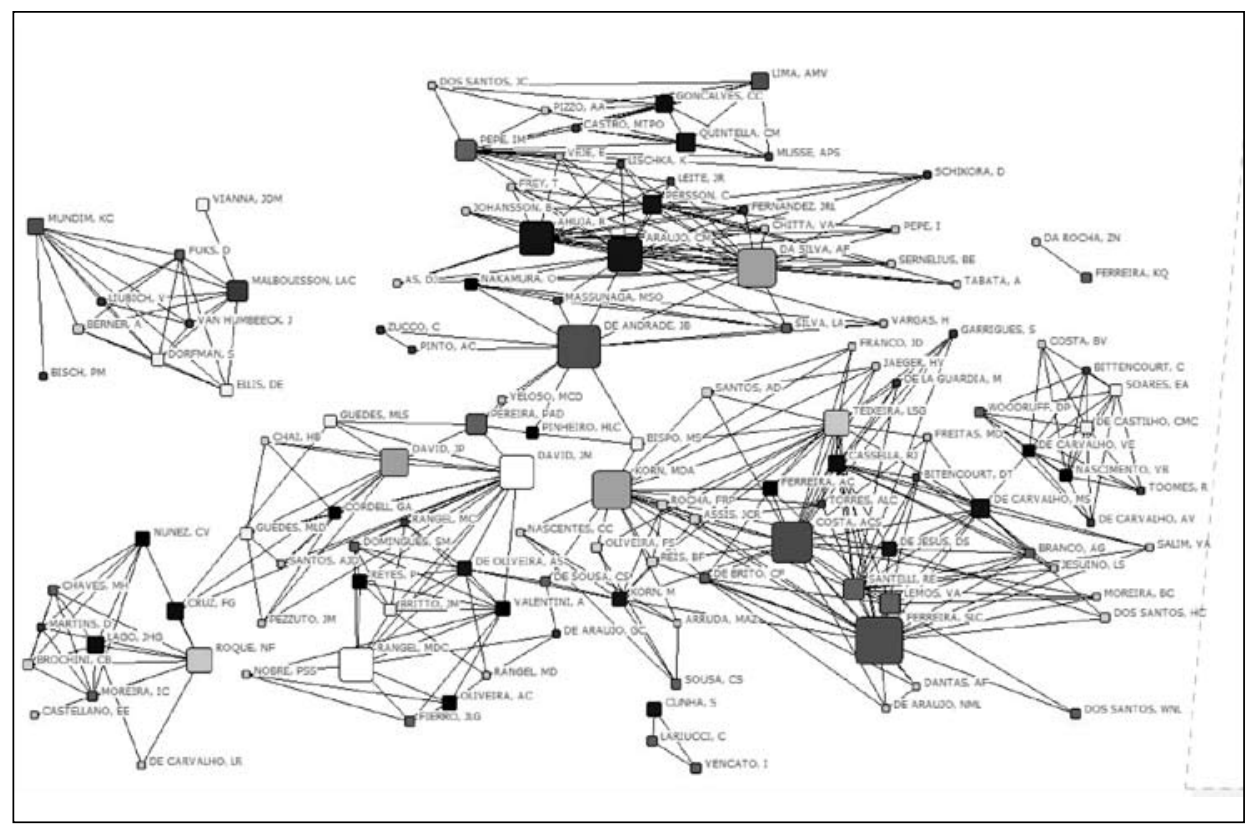

Source: Prepared by the authors based on the research results, 2009.

Despite its enormous growth, from 61 to 247 authors, this network became more fragile as can be seen in figure 6 and table 2 as its number of cutpoints increases (including now De Oliveira, A. S.; Cruz, F. G.; Pepe, I. M.; Bispo, M. S. and Dos Santos, H. C., in addition to de Andrade), its density falls from $7.22 \%$ to $1.37 \%$ and the average distance between their authors rises from 2.28 to 4.32 .

The period also marks the urge for new leaders such as Korn, M. D. A.; David, J. P.; Rangel, M. D. C.; Araujo, C. M.; among others.

In terms of centrality, there was a clear shift in the composition of the characters involved. In the first period analyzed, the highest degree centrality was that of De Andrade, J. B., in the following periods Ferreira, S. L. C. occupies this position. The table shows the growing and constant importance of Ferreira, S. L. C. in the three centrality measures along the study periods. 
By the other hand, Costa, A. C. S. sees a growth in his degree and closeness, although his betweenness falls to zero, indicating that he loses power in his capacity to intermediate between one or more authors who are not directly connected. This was probably a result of his retirement. Curiously, De Andrade, J. B. grows steadily in closeness and betweenness, while dropping considerably in degree. These results seem to indicate that the latter researcher became a more selective author in terms of co-authorship, despite publishing with a growing number of groups, maintaining a strategic position in terms of his articulation with the network as a whole.

Table 2

Centrality evolution from three main authors

\begin{tabular}{|lccc|}
\hline \multicolumn{4}{c|}{$1994-1998$} \\
\hline ID & De Andrade, J. B. & Ferreira, S. L. C. & Costa, A. C. S. \\
Degree & 34.0 & 32.0 & 30.0 \\
Betweenness & 1054.42 & 527.48 & 365.73 \\
Closeness & 1691.0 & 1696.0 & 1697.0 \\
\hline \multicolumn{4}{c}{$1999-2003$} \\
\hline ID & De Andrade, J. B. & Ferreira, S. L. C. & Costa, A. C. S. \\
Degree & 36.0 & 39.0 & 33.0 \\
Betweenness & 5603.42 & 1115.90 & 488.11 \\
Closeness & 50014.0 & 44008.0 & 44007.0 \\
\hline \multicolumn{4}{c}{ 2004-2008 } \\
\hline ID & De Andrade, J. B. & Ferreira, S. L. C. & Costa, A. C. S. \\
Degree & 21.0 & 97.0 & 52.0 \\
Betweenness & 14692.25 & 10976.89 & 0.00 \\
Closeness & 404887.0 & 405529.0 & 405553.0 \\
\hline
\end{tabular}

Source: Prepared by the authors based on the research results, 2009.

\section{Qualification period (2004 to 2008)}

The qualification period (marked by the effort from the graduation program from the Chemistry Institute to increase its productivity in order to reach concept 6 by Capes) shows an enormous growth and a rise in number of authors 
from 247 to 669 . Figures 7 and 8 illustrate this period. The first shows all nodes with at least two co-authorships, which include, as in the other periods, groups from other academic units of the UFBA, now mainly in the areas of collective health and physics (two groups each), immunology, medicine, molecular biology; the Polytechnic School and others. Despite the diversity in teaching units, it can be seen that all of them have at least one interconnection with the remaining ones, which reinforces the idea of non-redundant knowledge, typical of small worlds networks as discussed before.

Scientific knowledge network (at least two co-authorships) in chemistry at the UFBA between 2004 and 2008

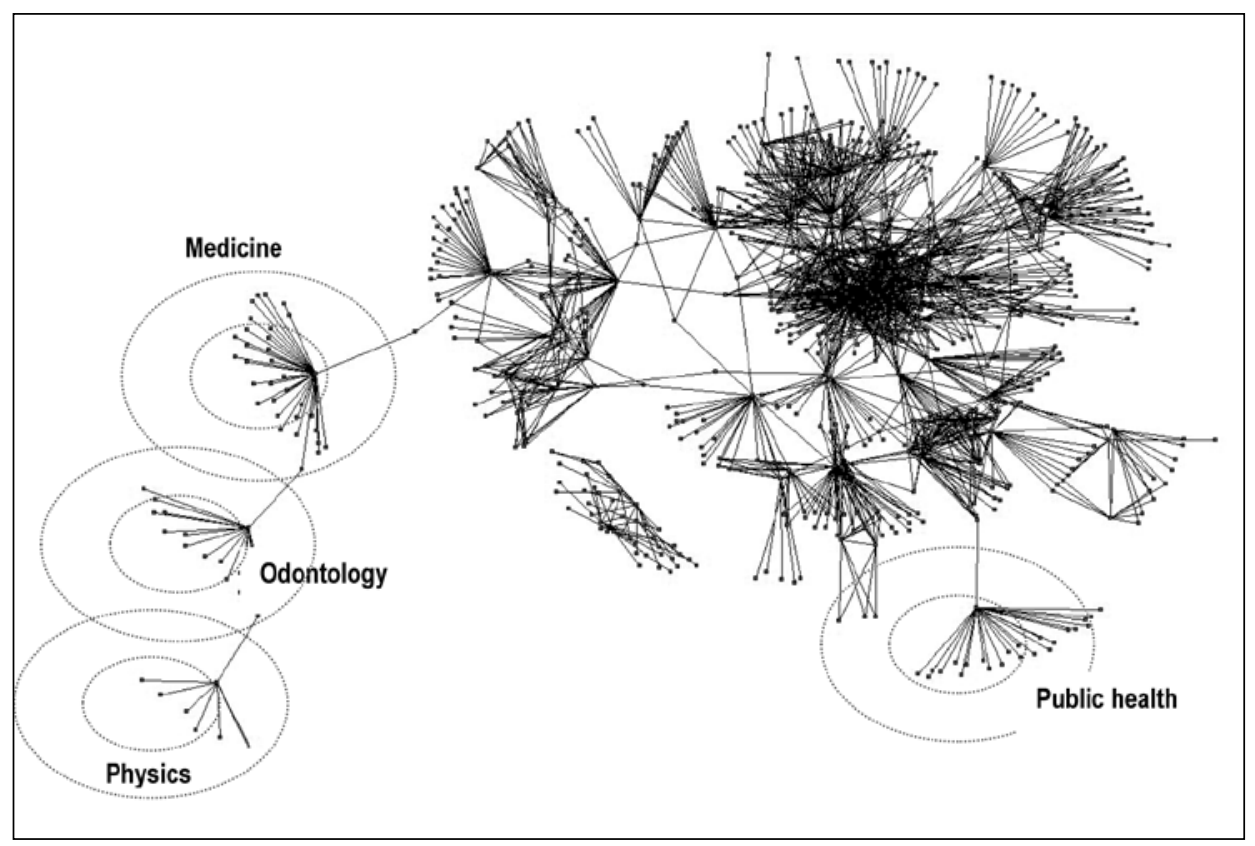

Source: Prepared by the authors based on the research results, 2009.

Figure 7 shows the frailty of many of these groups in terms of their competencies in chemistry for the reason that they have only one single tie with the chemistry area, meaning that in case of lack of those ties, all the remaining ones would not have one single paper indexed as chemistry. Among others, these ties are represented by the following researchers: Barreto, M. L. (collective health); Pinheiro, F. L. B. (odontology); Silva, M.; Badaró, R. T. 
(School of Medicine); Rangel, M. D. C. (Institute of Chemistry); Da Rocha, Z. N.; Mattedi, S. and Lima, A. M. V. (other units).

Figure 8 shows a more significant reduction of frailty in the specific network of co-authorship based in the Chemistry Institute Graduation Program, increasing the cohesion around Ferreira, S. L. C.

\section{Figure 8}

Scientific Knowledge Network (at least ten co-authorships) in Chemistry at the UFBA between 2004 and 2008

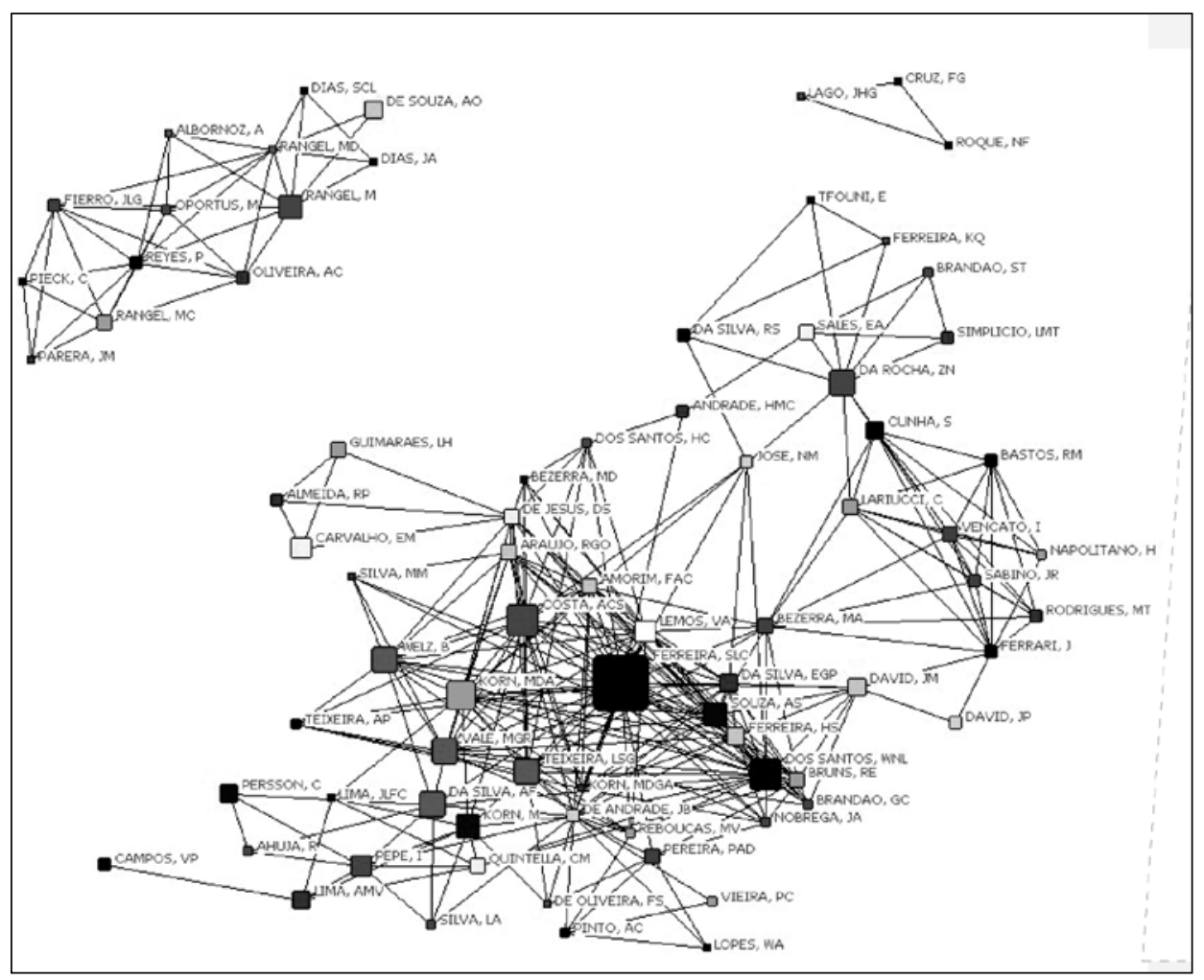

Source: Prepared by the authors based on the research results, 2009.

At the same time the centrality of De Andrade, J. B. is reduced in terms of degree while Costa, C. S. and Ferreira, S. L. C. increase their centrality, as shown in table 2, where the increase of Ferreira, S. L. C.'s betweenness centrality by a factor of ten in relation to the previous period deserves to be highlighted. 
Figure 8 also shows the rise of a second highly productive group in the Chemistry Institute centered around Rangel, M. It is also interesting to note that, in this period, aside from a large number of authors and co-authors, there arose new leaderships, with growing results not only in terms of centrality, but probably also in non-redundant information exchange within the network as mentioned in the literature. Probably this new network configuration will favor the search for more central objectives of the graduation program.

The changes in the network structures as a whole reveal greater maturity of the UFBA's knowledge network in chemistry confirming the nickname chosen for the period (qualification period). Figure 8 also makes clear that several other leaderships emerged in the last period and now confirms their consolidation.

With the mapping and studies on the configuration of the UFBA's knowledge network on chemistry, it is necessary to examine the dynamics of the scientific production in smaller public research institutions in the state, as well the influence of the UFBA on them.

\section{The UFBA's influence on chemistry knowledge networks at the Uneb and Uesc}

Among the six public universities in Bahia, the choice of the Uneb was straight on as it has the second largest and second longest-running graduation program in chemistry in Bahia. On the other hand, the Uesc was chosen exactly for the opposite reason, as it has no graduation program in this area, despite its considerable production (in accordance to ISI-WoK classification ${ }^{11}$ ).

The Uneb's Graduate Program in Applied Chemistry (Master's Degree level), was created in 2006, focusing on solid state chemistry and analytical chemistry. On the other hand, the Uesc only has an undergraduate course in the field. Most of the researchers in its network of co-authorships in chemistry are, in fact, linked to graduation programs in physics and molecular biology. ${ }^{12}$

Table 3 shows the percentile of the UFBA's network authors in the two networks for each period of analysis. It is important to highlight that the Uesc

\footnotetext{
${ }^{11}$ The periods of analysis for these two networks will be the same used to analyze the UFBA's network.

${ }^{12}$ It seems that with the establishment of the Center for Oceanographic Studies in 2005, the Uesc opened up new possibilities for researching in chemistry as it focuses on subjects such as marine pollution, marine biogeochemistry and marine analytical chemistry.
} 
only had production in chemistry in the last two periods (1999-2003 e 20042008), while the Uneb is present in all of them.

Table 3

Participation (\%) of the UFBA's network's authors in the Uneb and Uesc networks

\begin{tabular}{|lccc|}
\hline & $1994-98$ & $1999-2003$ & $2004-08$ \\
\hline Uneb & 27.27 & 24.24 & 12.63 \\
Uesc & - & 0 & 13.13 \\
\hline
\end{tabular}

Source: Prepared by the authors based on the research results, 2009.

It can be seen that the UFBA's participation on the Uneb and Uesc is significant as it is present (with expressive percentile) in all three periods of the Uneb's production, although showing a much smaller participation in the Uesc. However, taking this kind of analysis now to the percentage of co-authorships, table 4 shows a much higher participation of the largest university over the smaller ones.

Table 4

Participation (\%) of UFBA co-authorships in the scientific production of the Uneb and Uesc networks

\begin{tabular}{|lccc|}
\hline & $1994-98$ & $1999-2003$ & $2004-08$ \\
\hline Uneb & 50 & 45.28 & 19.52 \\
Uesc & - & 0 & 18.67 \\
\hline
\end{tabular}

Source: Compiled by the authors based on the research results, 2009.

As can be seen, almost half of the Uneb's production had a co-authorship from the UFBA's network in the first periods, falling to less then half in the latter. At the same time, the Uesc goes from nil to almost $20 \%$ from the second to the third period of analysis.

In order to check this influence, the software Ucinet was used to measure the leaderships on the two networks based upon their centralities. The results seem to be coherent with the last ones. In the 1999-2003 period none of the ten highest degree centralities on the Uesc network belonged to a member of the UFBA's net and in the following period it changed and reached almost $20 \%$. In terms of closeness, none of the periods show a UFBA resear- 
cher among the top ten in any of the periods, while betweenness centrality presented a similar situation, changing a little bit only in the last period. These results together with those shown in tables 3 and 4 show that the UFBA's network had little influence on the Uesc's net, revealing that researchers from each network are quite distant from each other, having, at most, $20 \%$ of the highest posts in degree and betwenneess centralities along the whole timespan of this study. These last results may possibly be due to a dependence on the UFBA's research infra-structure, mainly in terms of sophisticated scientific equipment.

The Uneb's network presented completely different results. Table 4 shows that half of its networks co-authorships are with the main university's net in the first two periods, when the participation of the last in terms of top ten centralities seems to reveal quite a dependence on the Uneb's networks in relations to the UFBA's, with $40 \%$ of its higher centrality ties being represented by the UFBA's researchers. Later on, these numbers fall to around $20 \%$ (although showing a UFBA professor as the one with the highest degree centrality). This fall seems natural, since both networks grew very quickly. In the last period, the UFBA's participation in the top-ten rankings rose to 30\% average. The story of closeness centrality however is the other way around as it goes from two to four and then to five authors among the top-ten during the periods under study. Finally, the betweenness centrality of the UFBA's net members is quite high throughout the periods. Again, this could be due to the availability of equipment at the UFBA.

In order to extract some more learning about scientific knowledge networks, this paper will now discuss the application of the small worlds concept to the three networks studied here.

\section{The chemistry networks in state of Bahia as a small worlds phenomenon}

As noticeable in figures 5, 6, 7 and 8 the UFBA networks are not shown to be thoroughly connected, always revealing a larger size group, and other small groupings around it. On the other hand, with the network analysis, it is noticeable that while it rises in size, it shows a tendency to configure itself as small worlds. In the first period, 1994 to 1998, the existence of several small groups was identified.

The tendency towards the small worlds configuration is mainly indicated in periods 1 and 3. The most clearly noticed fact in the period of 1999 to 
2003 while the gobal density was low (1.37\%), the average distance reached its peak (4.32) and the clustering coefficient reached its minimum (0.703). Table 5, below, complements the information from table 1, allowing some conclusions about the small worlds phenomenon.

Table 5

Small worlds statistics by period from the knowledge networks at UFBA

\begin{tabular}{|lccc|}
\hline & $\begin{array}{c}\text { Period 1 } \\
\text { 1994-98 }\end{array}$ & $\begin{array}{c}\text { Period 2 } \\
1999-2003\end{array}$ & $\begin{array}{c}\text { Period 3 } \\
\text { 2004-08 }\end{array}$ \\
\hline Number of authors & 61 & 247 & 669 \\
\hline Observed data & & & \\
Average of ties per author (k) & 4.202 & 4.659 & 4.81 \\
$P L:$ average distance & 2.28 & 4.32 & 3.7 \\
Maximum distance (diameter) & 6 & 11 & 9 \\
CC: clustering coefficient & 0.747 & 0.703 & 0.714 \\
Random data & & & \\
CC: coefficient of expected clustering $(k / n)$ & 0.069 & 0.019 & 0.007 \\
$P L:$ expected average distance $(\ln (n) / \ln (k))$ & 2.86 & 3.58 & 4.14 \\
Indicators & & & \\
$P L$ rate (PL real / PL random) & 0.79 & 1.21 & 0.89 \\
CC: rate (CC real / CC random) & 10.84 & 37.27 & 99.31 \\
Q: small worlds coefficient $(C C$ rate/ $P L$ rate) & 13.64 & 30.89 & 111.17 \\
\hline
\end{tabular}

Source: Prepared by the authors based on research results, 2009.

From the small worlds statistical analysis presented in table 5, can be seen that the networks have low density, however, there is elevated clustering coefficient (CC) indexes, indicating the formation of local cohesion. Moreover, the groups are largely bound by few connections and the average distances (PL) presented in the three periods are low, not surpassing five steps for one actor to access another, indicating a possible great dynamism in information exchange. It is also interesting to observe that the network in period 3, although the largest in size (669 authors), also has a larger clustering coefficient than in period 1 (when it had 61 authors), which seems to confirm small worlds formation and the possibility of existing local cohesion in a disperse network, with low global density. 
Thy hypothesis of the presence of the small worlds phenomenon in scientific knowledge networks from the UFBA is also confirmed by the formation of indicators, where the PL rate is around 1, the CC rate is considerably higher than 1 (also growing longitudinally) and the $\mathrm{Q}$ coefficient is very expressive, being well above 1 (mainly in period 3).

Once the small worlds formation has been characterized in the UFBA's net, it is important to have a look at how the other networks behave. This behavior can be seen in tables 6 and 7 below.

Table 6

Small worlds statistics by period in knowledge networks at the Uesc

\begin{tabular}{|lccc|}
\hline & $\begin{array}{c}\text { Period 1 } \\
1994-98\end{array}$ & $\begin{array}{c}\text { Period 2 } \\
1999-2003\end{array}$ & $\begin{array}{c}\text { Period 3 } \\
\text { 2004-08 }\end{array}$ \\
\hline Number of authors & - & 66 & 103 \\
\hline Density & - & $6,74 \%$ & $2,52 \%$ \\
Observed data & & & \\
Average of ties per author $(K)$ & - & 11.51 & 10.34 \\
$P L:$ average distance & - & 2.86 & 3.16 \\
Maximum distance (diameter) & - & 7 & 8 \\
CC: clustering coefficient & - & 0.09 & 0.08 \\
Random data & - & & 0.03 \\
CC: expected clustering coefficient $(k / n)$ & - & 4.27 & 4.64 \\
$P L:$ expected average distance $(\ln (n) / \mathrm{ln}(k))$ & - & & \\
Indicators & - & 0.67 & 0.68 \\
$P L:$ rate (real $P L$ lavatory $P L)$ & - & 2.80 & 5.29 \\
CC: rate (real CC lavatory CC) & - & 4.18 & 7.77 \\
Q: small worlds coefficient $(C C$ rate/PL rate) & & & \\
\hline
\end{tabular}

Source: Prepared by the authors based on research results, 2009.

It is easy to see in table 6 that the Uesc's network presents the small worlds configuration in both periods. As its clustering coefficient rate and small worlds coefficient (Q) are high and its PL rate is below one.

Unlike the UFBA and Uesc tendency, the Uneb did not present the formation of small worlds in its network (table 7), although it was observed that in the second period its clustering coefficient rate (CC rate) and its small worlds coefficient (Q) were also slightly above 1.0. It is also interesting to note that in period 3, the average distance (PL) was greater in the analyzed period (2.86), despite the smaller clustering coefficient (CC), which may indicate a single 
tendency (between the institutions studied here) towards the dispersion of the network without the simultaneous formation of cohesive sub-groups.

Table 7

Small worlds statistic by period in knowledge networks at the Uneb

\begin{tabular}{|lccc|}
\hline & $\begin{array}{c}\text { Period 1 } \\
1994-1998\end{array}$ & $\begin{array}{c}\text { Period 2 } \\
\text { 1999-2003 }\end{array}$ & $\begin{array}{c}\text { Period 3 } \\
\text { 2004-2008 }\end{array}$ \\
\hline Number of authors & 33 & 39 & 96 \\
\hline Density & $13,53 \%$ & $10,98 \%$ & $5,93 \%$ \\
Observed data & & & \\
Average of ties per author $(K)$ & 8.46 & 7.42 & 12.92 \\
PL: average distance & 2.46 & 2.59 & 2.89 \\
Maximum distance (diameter) & 5.00 & 5.00 & 7.00 \\
CC: clustering coefficient & 0.19 & 0.35 & 0.11 \\
Random data & & & \\
CC: expected Clustering Coefficient $(k / n)$ & 0.24 & 0.18 & 0.11 \\
PL: expected average distance $(\ln (n) / \ln (k))$ & 1.66 & 1.85 & 1.85 \\
Indicators & & & \\
PL: rate (real $P L$ lavatory $P L)$ & 1.48 & 1.40 & 1.56 \\
CC: rate (real CC lavatory CC) & 0.79 & 1.93 & 0.96 \\
Q: small world coefficient $(C C$ rate/PL rate) & 0.53 & 1.38 & 0.62 \\
\hline
\end{tabular}

Source: Prepared by the authors based on research results, 2009.

In a broad view, by analyzing the networks of the three universities, we may conclude that as the number of authors increases, the global density of the networks decreases, making them more disperse. However, according to the analysis conducted in this study, it can be seen that there is a strong tendency from the knowledge networks of the UFBA and Uesc to behave as small worlds for their expressive local concentrations. These findings seem to confirm a healthy functioning of these two networks (Uzzi and Spiro, 2005) as producers of knowledge, despite raising doubts as to their affectivity at the Uneb.

Comparing the three networks, it also can be seen that the UFBA's has much higher Small Worlds Coefficients (Q), reaching 111.17 during its third period, while in the same period the Uesc also reaches its higher $\mathrm{Q}$ which, however, is only 7.77. These data seem to show a much higher possibility of information exchange and non-redundant information exchange in the UFBA's net, as well as a higher level of local cohesion that would appear to mean more effective research groups. 


\section{Conclusions}

This paper is based on research derived from a technological innovation mapping project in the state of Bahia, and its goal was understanding the dynamics in scientific knowledge generation at the Universidade Federal da Bahia (UFBA) (Federal University of Bahia) and its influence on smaller state public universities in the area of chemistry.

By analyzing exploratory research conducted on the State's indexed scientific production, in the period of 1970 to 2008, it was possible to identify that the UFBA is by far the most productive research institution in the State. With the main focus on this university, a new research phase was accomplished with the intent of mapping its scientific knowledge network in one specific area. The chosen area was that of chemistry. Later, the participation of the researchers from the UFBA's network was investigated in the knowledge networks of another two smaller universities: Universidade do Estado da Bahia (Uneb) (State of Bahia University) and Universidade Estadual de Santa Cruz (Uesc) (Santa Cruz State University), aiming to understand their own dynamics and to form an initial picture of what the dynamics of the State's networks might be as a whole.

In the analyzed period, four intervals were established based on the exploratory research, being respectively 1970 to 1993 ; 1994 to $1998 ; 1999$ to 2003; and 2004 to 2008. The last three of these periods (those with the largest scientific production) were chosen to be discussed in the present paper.

The analysis of the UFBA, Uneb and Uesc networks of scientific knowledge in chemistry throughout the three periods allowed for some conclusions to be drawn concerning the different university networks, the main roles of their researchers and also general hints about knowledge network dynamics, the main project methodology and needs for future research.

In terms of the universities' networks, there was tremendous growth in all of them during all the periods analyzed (1994 to 2008), especially that of the UFBA, which grew from 61 nodes to 667 (approximately 993\%) in fifteen years. During the same period, the Uneb jumped from 35 to 113 authors (approximately 223\%), and the Uesc from 89 to 209 nodes (approximately 135\%). Therefore, the UFBA, despite its already much larger size also saw more expressive growth.

It is interesting to observe that the UFBA was very much dependent on three central authors in the 1994-1998 period. Throughout the following periods, its network clearly became more independent of them, even considering that their individual production improved, showing a clear process of ripening and becoming a mature network. 
The main author's trajectories seem to follow different trajectories, with one of them showing reduced degree centrality at the same time that its betweeneess centrality increases (except in Costa, A. C. S. case, as seen before). This behavior seems to be related to more selective co-authorship behavior. All three of these authors remain central to the UFBA network over time. All of them are present in the other networks, mainly the Uneb's, but with time their centrality in these networks falls considerably.

Figure 9 illustrates the high interdependence of the two smaller networks on the UFBA's. In the image, all nodes in black are authors of the UFBA network.

\section{Figure 9}

The UFBA's networks members participation in Uneb's and Uesc's chemistry networks (2004-2008)



Source: Prepared by the authors based on research results, 2009.

Another important conclusion is that in all the studied periods, the results affirm the existence of the small worlds phenomenon in the UFBA scientific knowledge network. where, despite the increase in size and the low density of the global network, there is a considerable concentration of actors in local networks. This structure, in accordance with the theoretical references, hinders the flow of information and non-redundant knowledge between the component groups of the network, since there is the participation of intermediating agents that become responsible for the connection between them. This phenomenon is also evident in the case of the Uesc, but curiously not in the case of the Uneb. In the Uesc network, it was not represented in such an expressive emanner as it was in the UFBA networks, since their (Q) coefficients are more inferior to those observed at the larger university. These results would appear to indicate that there is a different research environment 
in all three cases. Theoretically, the UFBA's is more in accordance with what should be a knowledge construction environment with high local cohesion (strong research groups) and low global density that guarantee the necessary non-redundant information. Apparently the Uneb's network fails to accomplish the first aspect (as its local cohesion does not grow over time, indicating unconsolidated research groups). On the other hand, the Uesc's net is in accordance with both small worlds phenomenon requirements, but only slightly in terms of its environment as a whole.

The indicators in this paper presented for the three networks also show a tendency on their part towards homophyly and possibly to isomorphism, although there is no ultimate confirmation of this tendency, particularly in the case of the Uneb, which had quite different dynamics from the two other institutions. Such characteristics are, again, typical of research environments, as mentioned in the theoretical references. They seem to indicate that as the larger research groups (and their central researcher) generate new groups and leaderships, each tends to behave as a network itself, but at the same time it maintains some resemblance to the original group or clique. This kind of behavior will be analyzed more in depth during the continuation of this research as the Uesb is included, as it is presently the main research network derived from the UFBA.

By evaluating the network evolution from the UFBA throughout the studied periods, a paradoxal phenomenon is observed, however, common to knowledge networks mentioned in the theoretical references: the decrease in frailty in the central network groups, followed by the maintenance of frailty from the peripheral groups. Figure 7 illustrates this frailty, showing many of these groups interconnected only by cut-points. ${ }^{13}$

As said before, knowledge networks, as well as the majority of social networks, have cohesion as one of their main elements of analysis. Figure 7 shows a network with strong local cohesion and density in opposition to its low global cohesion. With the continuation of this study, it will be possible to test the hypotheses that, at least some of these authors that act as cut-points, while they frailly connect to the chemistry groups, they strongly bind to other groups in other areas, such as physics, medicine, collective health and so on, characterizing a typical small worlds network in several areas of knowledge within the university.

\footnotetext{
${ }^{13}$ It is important to highlight that, even though the existence of cut-point authors is a risk for the network integrity, those actors represent important connections between different groups. So, the cut-points authors are extremely important for the knowledge transmission.
} 
Thus, by raising scientific knowledge networks in the area of chemistry at UFBA, it was possible to identify relevant information about the area of chemistry at the university and verify its influence on other of its areas of knowledge, but also mainly on two of the remaining public research institutions in the state of Bahia (as part of a larger project) with specific scientific knowledge networks on chemistry. The chemistry area as a case study was useful also as a test to the methodology which turned out to be adequate. Certainly, with the possibility of replica and in the deepening of the applied methodology presented herein, this research into other areas of the Bahia's research institutions, a reasonable mapping of its competences and of their dynamics will be possible.

Some new research should also be done to confront the results of this paper's conclusions (and others of its kind) with the Brazilian National Council for Scientific and Technological Development Directory of Research Groups. This kind of study together, with some results from evaluating the dynamics of scientific knowledge networks may also bring relevant information for the creation of research policies at the level of the universities themselves.

\section{References}

BARAB, S., Thomas, M.; MERRILL, H. Online learning: from information dissemination to fostering collaboration. Journal of Interactive Learning Research, v. 12, n. 1, p. 105-143, 2001.

BARBOSA, M. T. S.; Byington, M. R. L.; Struchiner, C. L. Modelos dinâmicos e redes sociais: revisão e reflexões a respeito de sua contribuição para o entendimento da epidemia do HIV. Cadernos Saúde Pública, v. 16, n. 1, p. 37-51, 2000.

Brasil. Lei no 10.973, de 2 de dezembro de 2004. Diário Oficial da República Federativa do Brasil, Brasília, DF, 2 dez. 2004. Available at: <www.planalto.gov.br/ Ccivil_03/_Ato2004-2006/2004/Lei/L10.973.htm>. Access in: Dec. 10, 2007.

BURT, Ronald S. Structural holes: the social structure of competition. Cambridge, Mass.: Harvard University Press, 1992.

CARVALHO, R. Q; CONSONI, F. L.; QUINTÃO, R.; VIEIRA, G. Mapping out technological capabilities in research institutions as tool for prospecting RandD outsourcing opportunities: a methodology developed for the RandD centre of a major car assembler. In: SIMPÓSIO DE GESTÃO DA INOVAÇÃO TECNOLÓGICA, 24. Proceedings..., 2006. 
; FURTADO, A.; BERNARDES, R.; FRANCO, E. Padrões de inovação tecnológica na indústria paulista: semelhanças e diferenças em relação aos países industrializados. São Paulo em Perspectiva, v. 13, n. 1, 1999.

CASAS, R.; GORTARI, R.; LUNA, M.; SANTOS, M. J.; TIRADO, R. La formación de conocimiento: uma perspectiva regional desde Mexico. Mexico: Anthropos, 2001.

DE NOOY, W.; MRVAR, A.; BATAGELJ, V. Exploratory social network analysis with Pajek. New York: Cambridge University Press, 2005.

DIDRIKSSON, A. La sociedad del conocimiento desde la perspectiva latinoamericana. In: ENCUENTRO DE ESTUDIOS PROSPECTIVOS REGIÓN ANDINA: SOCIEDAD, EDUCACIÓN Y DESARROLLO. Memorias... Medellín, 2003.

FURTADO, A. Indicadores de inovação e capacitação/aprendizagem tecnológica. São Paulo: Fundação Seade, 1996.

GIBBONS, M.; LIMOGES, C.; NOWOTNY, H.; SCWARTZAN, S.; SCOTT, P.; TROW, $\mathrm{M}$. The new productions of knowledge: the dynamics of science and research in contemporary societies. London: Sage Publications; New Delhi: Thousands Oaks, 1994.

GIDDENS, A. A constituição da sociedade. São Paulo: Martins Fontes, 1989.

GNYAWALI, D.; Madhavan, R. Cooperative networks and competitive dynamics: a sctrutural embeddedness perspective. Academy of Management Review, v. 26, n. 3, p. 431-445, 2001.

GRANOVETTER, M. Economic action and social structure: the problem of embeddedness. American Journal of Sociology, v. 91, p. 491-501, 1985.

HUANG, C.; ARUNDEL, A.; HOLLANDERS, H. Non-RandD innovation of manufacturing firms: theory and evidence from the third European community innovation survey. Proceedings... Brussels: Innova Innovation Watch/European Commission, 2008.

IBGE (Instituto Brasileiro de Geografia e Estatística). Technological innovation research 2005. Available at: <www.ibge.gov.br/home/estatistica/economia/ industria/pintec/ 2005.pdf>. Acessed in: June 24, 2008.

ISIWeb of Knowledge. Research platform. Available at: < http://apps.isiknowledge.com/ UA_GeneralSearch_input.do?product $=$ UAandsearch_mode $=$ GeneralSearchandSI $\mathrm{D}=1$ FboHcPAcomcP89pcK5andpreferencesSaved=>. Access in: Aug. 6, 2008.

LAVE, J.; WENGER, E. Situated learning: legitimate peripheral participation. Cambridge: University of Cambridge Press, 1991.

LAZZARINI, S. G. Mudar tudo para não mudar nada: análise da dinâmica de redes de proprietários no Brasil como "Mundos Pequenos". Revista de Administração Eletrônica, v. 6, 
n. 1, jan./jul. 2007. Available at: $<$ www.rae.com.br/eletronica/index.cfm?FuseAction= ArtigoandID $=3991$ andSecao $=\mathrm{F} \% \mathrm{C} 3 \% 93 \mathrm{RUMandVolume}=6$ andnumero $=1$ andA no $=2007>$. Access in: Oct. 4, 2009.

LIBERMAN, S.; WOLF, K. B. The flow of knowledge: scientific contacts in formal meetings. Social Networks, v. 19, n. 3, p. 271-283, 1997.

MACHADO-DA-SILVA, C. L.; ROSSONI, L. Persistência e mudança de temas na estruturação do campo científico da estratégia em organizações no Brasil. Revista de Administração Contemporânea, v. 11, n. 4, p. 33-58, 2007.

MOODY, J. The structure of a social science collaboration network: disciplinary cohesion from 1963 to 1999. American Sociological Review, v. 9, n. 2, p. 213-238, 2004.

NEWMAN, M. E. J. Scientific collaboration networks. I. Network construction and fundamental results. Physical Review, v. 64, n. 1, p. 1-8, 2001.

. Co-authorship networks and patterns of scientific collaboration. Proceedings of the National Academic Sciences, v. 101, n. 1, p. 5200-5205, 2004.

ROSSONI, L. Agência socialmente imersa em redes mundos pequenos: uma análise multinível da produtividade acadêmica. In: ENANPAD, 33. Anais... São Paulo, 2009.

; GARRIDO FILHO, E. R. Cooperação entre programas de pós-graduação em administração no Brasil: evidências estruturais em quatro áreas temáticas. Revista de Administração Contemporânea, v. 13, p. 366-390, 2009.

; MACHADO-DA-SILVA, C. L. Análise institucional da construção do conhecimento científico em mundos pequenos. Faces - Revista de Administração, v. 7, n. 1, p. 25-43, 2008.

ROWLEY, T.; BEHRENS, D.; KRACKHARDT, D. Redundant governance structures: an analysis of structural and relational embeddedness in the steel and semiconductor industries. Strategic Management Journal v. 21, p. 369-386, 2000.

SCOTT, J. Social network analysis: a handbook. London: Sage, 2000.

SEBASTIÁN, J. Análisis de las redes de investigación de América Latina con la Unión Europea. Recitec - Revista de Ciência e Tecnologia, v. 3, n. 2, p. 308-321, 1999.

TOMAÉL, M. I.; MARTELETO, R. M. Redes sociais: posições dos atores no fluxo da informação. In ENCONTRO NACIONAL DE PESQUISA EM CIÊNCIA DA INFORMAÇÃO (ENANCIB), 6. Florianópolis. Anais... UFSC, 2005, p. 1-11.

UZZI, B.; SPIRO, J. Collaboration and creativity: the small world problem. American Journal of Sociology, v. 111, n. 2, p. 447-504, 2005. 
WASSERMAN, S.; FAUST, K. Social network analysis: methods and applications. Cambridge: Cambridge University Press, 1994.

WATTS, D. J. Networks, dynamics, and small world phenomenon. American Journal of Sociology, v. 105, n. 2, p. 493-527, 1999a.

. Small worlds: the dynamics of networks between order and randomness.

Princeton: Princeton University Press, 1999b.

; STRONGATZ, S. H. Collective dynamics of "small-world" network. Nature, n. 393, p. 440-442, 1998. 